\title{
Terapia ocupacional e atuaçáo em contextos de vulnerabilidade social: distinçóes e proximidades entre a área social e o campo de atenção básica em saúde
}

\author{
Ana Paula Serrata Malfitano ${ }^{a}$, Pamela Cristina Bianchi ${ }^{b}$ \\ ${ }^{a}$ Doutora em Saúde Pública, Universidade de São Paulo - USP, Professora Adjunta do Departamento \\ de Terapia Ocupacional e do Programa de Pós-graduação em Terapia Ocupacional, \\ Universidade Federal de São Carlos - UFSCar, São Carlos, SP, Brasil \\ bResidente do Programa de Residência Multiprofissional em Saúde da Família e Comunidade, \\ Universidade Federal de São Carlos - UFSCar, Graduada em Terapia Ocupacional, \\ bolsista do Programa PIBIC/CNPq/UFSCar, 2010-2011, \\ Universidade Federal de São Carlos - UFSCar, São Carlos, SP, Brasil
}

\begin{abstract}
Resumo: Os centros urbanos no âmbito social brasileiro são caracterizados por realidades de grande desigualdade socioeconômica, trazendo para os técnicos de diferentes áreas, entre eles o terapeuta ocupacional, a atuação em contextos de vulnerabilidade social. Assim, a pesquisa teve como objetivo se aproximar e identificar as intervenções em terapia ocupacional social e aquelas na atenção básica em saúde, com o intuito de verificar as proximidades e as distinções das atuações, quando realizadas em cenários de vulnerabilidade social. A pesquisa se deu no município de São Carlos-SP, a partir da entrevista com todas as terapeutas ocupacionais em atuação nas áreas selecionadas, sendo seis terapeutas ocupacionais no campo social e cinco terapeutas ocupacionais na atenção básica em saúde. Realizou-se também observação participante de atividades de terapeutas ocupacionais na área social e na atenção básica em saúde. A partir da observação da prática e análise temática do discurso das terapeutas ocupacionais, observou-se uma diferenciação significativa quanto aos objetivos e recursos utilizados pelas profissionais mesmo quando desempenhadas no mesmo território caracterizado por grande vulnerabilidade social. Conclui-se que há especificidades claras em cada campo, sendo que se faz necessária a identificação das diferenciações e dos objetivos de cada intervenção. Compreender as práticas desempenhadas permite aproximar-se da identidade do profissional e de suas maiores contribuições que possam vir a ser executadas nos diferentes setores.
\end{abstract}

Palavras-chave: Terapia Ocupacional/Tendências, Terapia Ocupacional Social, Atenção Primária à Saúde, Vulnerabilidade Social.

\section{Occupational therapy and action in social vulnerability contexts: proximities and distinctions between the social field and the primary health care area}

\begin{abstract}
In the scenario of the Brazilian social reality urban centers are characterized by high socioeconomic inequality, this fact makes social/health professionals of many areas, including occupational therapists, take part in social vulnerability contexts. Thus, the objective of this study was to approach and identify interventions in social occupational therapy and primary health care in order to verify the proximities and distinctions between the actions, when performed in social vulnerability contexts. This research was carried out in São Carlos, state of São Paulo, based on semi-structured interviews with all occupational therapists working in the selected areas: six therapists working in the social field and five from the primary health care area. We have also observed in situ the activities
\end{abstract}

Autor para correspondência: Ana Paula Serrata Malfitano, Laboratório METUIA, Departamento de Terapia Ocupacional, Universidade Federal de São Carlos, Rod. Washington Luís, Km 235, SP-310, CEP 13565-905, São Carlos, SP, Brasil, e-mail: anamalfitano@ufscar.br Recebido em 13/3/2013; $1^{\text {a }}$ Revisão em 3/6/2013; $2^{\text {a }}$ Revisão em 22/6/2013, Aceito em 25/7/2013. 
of occupational therapists in the social and primary health care areas. Based on the observation of the occupational therapists' practices and on the thematic analysis of their speech, we found a significant difference between the objectives and resources used, even when performed in the same territory of social vulnerability. It was possible to conclude that there are clear specificities in each field, and that it is necessary to identify the differences and objectives of each intervention. The understanding of the practices performed allows us to approach the identity of the professionals and their major viable contributions to different sectors.

Keywords: Occupational Therapy/Trends, Social Occupational Therapy, Primary Health Care, Social Vulnerability.

\section{Introdução}

Partindo da definição que a terapia ocupacional é uma profissão que realiza sua intervenção no âmbito da saúde, do trabalho, da educação e na esfera social, a qual reúne:

[...] tecnologias orientadas para a independência e autonomia de indivíduos que por diversas problemáticas ligadas a fatores físicos, sensoriais, mentais, psicológicos e/ou sociais demonstram dificuldade na inserção e participação na vida social [...] (UNIVERSIDADE..., 1997),

propóe-se discutir as especificidades, os pontos de congruências e as diferenciaçóes entre as intervençóes terapêutico-ocupacionais no campo social e na atenção básica em saúde.

A presente pesquisa voltou seus questionamentos para os objetivos e os recursos utilizados pelo terapeuta ocupacional para o desenvolvimento de sua prática profissional em dois campos de atuação que se autointitulam como interventores no território. Ambos propóem o território como lócus privilegiado de intervenção na medida em que utilizam o local de vida das pessoas como espaço de atuação.

Um importante pesquisador acerca do conceito de território, avançando na discussão para além das questôes sobre a delimitação geográfica, foi Milton Santos (1926-2001). Segundo Faria e Bortolozzi (2009), a obra do pesquisador renova o pensamento geográfico, uma vez que sua concepção de território contribuiu para a centralidade da discussão sobre as desigualdades sociais e os aspectos socioculturais, relacionando espaço e chances de vida. No campo da saúde, alguns estudos, ampliando a compreensão acerca dos processos de saúde e doença, extrapolaram a discussão acerca dos processos biológicos, incluindo os fatores sociais, econômicos, políticos e culturais como fundamentais para o planejamento e implantação de ações em saúde, trazendo a noção de território como ponto relevante para as diretrizes políticas.

A respeito dos fatores sociais e culturais, Haesbaert (2005) afirma que a noção de território está ligada ao significado que as pessoas atribuem ao lugar que ocupam desde a utilizaçáo da terra ao modo que se organizam no espaço que vivem.

A partir de tais referências, compreende-se território como sendo um espaço de possibilidades de expressóes concretas de vida, dentro do qual é possível conhecer e atuar sobre os sentidos atribuídos aos diferentes elementos cotidianos, incluindo a produção de valores e trocas sociais. Um dos principais lugares de produção de saberes sobre a vida, sobre os problemas e sobre as possibilidades de criação de soluçôes (OLIVER et al., 2001).

Considera-se uma estreita relação entre o debate conceitual sobre território e as intervençóes em terapia ocupacional, na medida em que esse profissional dedica-se a intervençóes em espaços do cotidiano dos grupos com os quais intervém. Segundo Barros (2004), é necessário ao trabalho do terapeuta ocupacional conhecer as culturas locais específicas de seus espaços de intervenção, buscando uma ruptura de procedimentos técnicos preestabelecidos. Além disso, a formação interdisciplinar do terapeuta ocupacional torna-se um fator estimulante no desenvolvimento de açóes que estejam focadas na esfera individual e na coletiva (JARDIM; AFONSO; PIRES, 2008).

\subsection{A área social}

A área social vem sendo reconhecida e normatizada pela categoria dos terapeutas ocupacionais tendo, em 2010, recebido uma resolução do Conselho Federal de Fisioterapia e Terapia Ocupacional (Coffito). Segundo a Resoluçáo no 383/2010, art. 10 (CONSELHO..., 2010, p. 80), o terapeuta ocupacional desenvolve seu trabalho no:

[...] campo social por meio de atividades como tecnologias de mediação sócio-ocupacional, desenvolvendo estratégias de pertencimento sociocultural e econômico, organizaçóes da vida cotidiana, projetos de vida, entre outros; com intuito de fortalecer as redes de suporte social e de trocas afetivas, econômicas e de informaçóes, com pessoas, famílias ou grupos. 
A ação da terapia ocupacional no campo social prevê um recorte metodológico específico para o qual se voltam açóes para públicos que têm a vulnerabilidade social como eixo central de sua demanda de atenção. Dessa forma, é necessário trabalhar e desenvolver instrumentos e métodos voltados à interpretação da realidade pessoal-social e à atuação em um universo complexo de interaçóes e interconexóes (LOPES et al., 2010).

Para a efetivação do trabalho do terapeuta ocupacional social, parte-se do princípio de que é necessário que haja o reconhecimento do outro como sujeito autônomo, como ideia fundamental e princípio norteador, vendo-o como interlocutor do processo que se promove. Para tanto, propóe-se o desenlace da mediação saúde-doença, a partir do extravasamento do campo da saúde e confronto com as realidades sociais. Dessa forma, a intervenção no âmbito social prevê uma atuação embasada em saberes plurais e em açóes voltadas ao coletivo, à cultura específica local e à vida cotidiana da comunidade inserida, utilizando-se da atividade como mediadora das relaçôes e eixo organizador da intervenção (BARROS, 2004; BARROS; GHIRARDI; LOPES, 2002).

Segundo Lopes (2006), para as ações em terapia ocupacional social faz-se necessário o conhecimento da realidade da população que se acompanha, das suas necessidades e das maneiras com que essa populaçáo visualiza o mundo ao seu redor, o seu cotidiano. Portanto, o conceito de território permeia a intervenção como um importante espaço de ação. Barros (2004, p. 96) afirma que "[...] é preciso conhecer como vivem, onde moram, como se constroem as relaçôes familiares, os laços de amizade e os desejos [...]" a fim de se produzir estratégias eficazes para o trabalho.

Para tanto, o intuito do trabalho do terapeuta ocupacional na área social tem sido fomentar estratégias para o fortalecimento das redes de suporte pessoais e social de sujeitos em contextos de vulnerabilidade social, com vistas à possibilidade de construção de perspectivas de futuro, a partir de maior autonomia e inserção social, embasados nos pressupostos do exercício da democracia e dos direitos decorrentes da cidadania (LOPES et al., 2010; LOPES; BORBA; CAPPELLARO, 2011).

\subsection{Atenção Básica em Saúde}

As açôes no cenário da saúde, por sua vez, são aquelas que concentram um maior número de profissionais terapeutas ocupacionais no Brasil, sendo que o Sistema Único de Saúde - SUS, desde sua institucionalização, impulsionou a inserção desse profissional na assistência pública em saúde. Tal fato é consequência da ampliação do atendimento aos grupos populacionais no âmbito do SUS, na prerrogativa, conforme definido pela carta constituinte, do direito à saúde para todos (BRASIL, 1990).

No âmbito da atenção básica em saúde, o SUS tem adotado, desde 1996, uma estratégia de reorientação do modelo assistencial: a Estratégia de Saúde da Família (ESF). É pensado no trabalho por meio de equipes multiprofissionais, responsáveis pelo acompanhamento de um número específico de famílias, alocadas em uma área geográfica delimitada. As equipes de saúde da família atuam com açóes de promoção da saúde, prevenção, recuperação, reabilitação de doenças, e na manutençáo da saúde desta comunidade (BRASIL, 2010).

Trata-se da priorização desse nível de atenção para organização do sistema de saúde, ocorrida, inclusive, por incentivos financeiros do Ministério da Saúde destinados para os municípios, com o intuito de direcionar as açóes desenvolvidas. Assim, as discussóes para as diversas categorias profissionais em atuação no campo da saúde, entre elas o terapeuta ocupacional, voltam-se para as suas contribuiçôes no nível da atenção básica em saúde.

Nesse contexto, em 2008 houve a criação dos Núcleos de Apoio à Saúde da Família (NASF) com objetivo de ampliar e articular açóes de saúde mental, reabilitação, promoção de saúde, orientaçôes nutricionais, atividades físicas e práticas corporais, assistência social, práticas integrativas e complementares e assistência farmacêutica. Através da incorporação de profissionais como assistentes sociais, educadores físicos, farmacêuticos, fisioterapeutas, fonoaudiólogos, terapeutas ocupacionais, psicólogos, entre outros (BRASIL, 2008).

Segundo Jardim, Afonso e Pires (2008), diversos profissionais atuam no nível básico de assistência em saúde compondo as equipes, estando presente, também, o terapeuta ocupacional. Cabe ao profissional atuar no território, considerando suas múltiplas potencialidades, como as residências dos sujeitos e, em especial, os espaços comunitários e sociais, com objetivo de ampliar o serviço de saúde para além de seus muros institucionais; informar os usuários sobre sua patologia e, mais que isso, o que pode ser feito para ajudá-lo, em toda comunidade, trazendo conhecimentos inovadores, desmistificando preconceitos e oferecendo um atendimento integral. Os objetivos são trabalhados por meio de atendimentos individuais ou em grupos, nos quais são utilizadas atividades para viabilizar, inserir e reinserir o sujeito na sociedade e em seu 
trabalho, além da troca de vivências e experiências; e por meio de açóes individuais, objetivando a solução de suas demandas, quanto à sua patologia, moradia, cuidadores, entre outras.

Assim, tendo por base a intervenção da terapia ocupacional no campo da atenção básica em saúde e na área social, essa investigação debruçou-se sobre a discussão acerca das diferenças e similaridades de intervenção, com vistas a pontuar as especificidades de cada área a partir de seus objetivos e recursos, bem como as semelhanças, quando direcionadas para um mesmo contexto de vulnerabilidade social e com proposiçóes teóricas de ação no território.

\subsection{Vulnerabilidade social e intervenções em Terapia Ocupacional}

O Brasil é um país que abarca fatores como: concentraçáo de renda; altos índices de analfabetismo; violência; desemprego; alimentação de baixa qualidade; precariedade no ensino público; entre outros, que evidenciam o alto grau de desigualdade social que descreve a situação de grande parcela da sociedade brasileira, levando-a, muitas vezes, a uma situação de rupturas da participação social. Tem-se, então, o desafio social do desenvolvimento de estratégias e açốes que promovam a efetivação dos direitos e a participaçáo decorrentes da cidadania dessa parcela da população (COTTA et al., 2007; LOPES, 2007).

Cabe, portanto, aos profissionais envolvidos com a defesa dos direitos e a efetivação de políticas sociais o fortalecimento de açóes e o investimento em pesquisas nesse campo, com intuito de produzir subsídios e tecnologias sociais que se dediquem à diminuição das desigualdades, além do incentivo e apoio à associação e participação na discussão sobre o acesso aos direitos e às condiçóes de vida (LOPES et al., 2008). Lança-se, portanto, o desafio aos profissionais, entre eles o terapeuta ocupacional, em criar metodologias, reflexôes e estratégias de intervenção para a atuaçáo no território, de acordo com as demandas locais encontradas, a fim de buscar a efetivação das políticas sociais de acordo com seus pressupostos pautados pelos direitos sociais (MALFITANO, 2005).

O estado de vulnerabilidade social é produzido na aliança da precariedade do trabalho com a fragilidade dos vínculos sociais, sendo uma categoria capaz de descrever a situação de uma grande parcela da população brasileira. Para Castel (1994), o espaço social pode ser analisado segundo dois eixos: o da relaçáo com o trabalho (variando de emprego estável à sua completa ausência) e o da inserção relacional (das redes sólidas de sociabilidade ao isolamento social).

Por conseguinte, considerando a predominância das políticas públicas em contextos de vulnerabilidade social, estudamos os objetivos e os recursos utilizados pelo terapeuta ocupacional para o desenvolvimento de sua prática profissional em uma região periférica da cidade de São Carlos, interior paulista.

O local estudado caracteriza-se por ser uma regiấo periférica urbana. Assinala-se como um local com visibilidade pela gestáo municipal, fato incentivado pelos níveis de pobreza local. Conta com uma rede de equipamentos sociais que, apesar de insuficientes, tem atuação local e previsão de crescimento. Um dos bairros componentes da regiấo possui um histórico de ocupação, entre 1977 e 1979, caracterizado pela irregularidade quanto à demarcação e à divisão dos lotes, assim como pela ilegalidade de suas novas construçôes, que se localizam cada vez mais próximas de uma grande área de risco e de preservação ambiental, chamada pelos moradores locais de "buracáo". Atualmente, com a ocupação desordenada do espaço urbano, o local é detentor dos maiores índices de vulnerabilidade social da cidade de São Carlos, no qual se observam pobreza, altos índices de violência, de desemprego, de uso de drogas, de baixa escolaridade, entre outros. Portanto, considerado como zona crítica, o território é cenário de preconceitos e estigmas para com seus moradores, exercido pelos demais munícipes locais (CAMPOS et al., 2003).

Por ser reconhecida com uma regiáo de vulnerabilidade social, realizou-se parte da presente pesquisa nesse local, na medida em que se buscou a discussão das açóes territoriais em terapia ocupacional em contextos de vulnerabilidade.

\section{Metodologia}

O referencial adotado de análise filia-se aos estudos teóricos da terapia ocupacional social no Brasil buscando identificar, em aspectos concretos da realidade, chaves de leitura que se dediquem à compreensão de questóes microssociais e suas interrelaçóes com o contexto macrossocial. Em outras palavras, parte-se de uma compreensão da necessária associação entre as dimensóes pessoal e social para que, a partir de uma perspectiva coletiva, se possa falar de intervençôes profissionais, como do terapeuta ocupacional, na complexa e múltipla contemporaneidade social (BARROS; GHIRARDI; LOPES, 2002). 
Utilizamos, como método de pesquisa, 11 entrevistas semiestruturadas e quatro meses de observação participante, sendo dois meses junto a uma terapeuta ocupacional na atenção básica em saúde e dois meses junto a uma terapeuta ocupacional em um serviço social.

As entrevistas objetivaram obter informaçóes contidas na fala dos atores sociais, relevantes para a compreensãio acerca das práticas desenvolvidas pelos profissionais. Segundo Meihy (1998), o discurso oral ou a história oral tem como matéria essencial a humanização das percepçóes, permitindo através de entrevistas, por exemplo, uma aproximação entre pessoas e instituições com o objetivo de conhecer suas visóes e práticas.

Paralelamente, a observação participante pode ser compreendida como uma técnica que se realiza através do contato direto do pesquisador com o fenômeno observado, para obter informaçóes sobre a realidade dos atores sociais em seus próprios contextos, bem como propiciar situaçôes de participação naquela realidade, favorecendo sua apreensão e debate sobre ela (MINAYO et al., 2002).

A observação participante na área social ocorreu junto às açóes de extensão e formaçáo do Projeto METUIA $^{1}$. As intervençóes aconteciam em um equipamento direcionado ao lazer e à convivência da população juvenil.

Conjuntamente, acompanhou-se a dinâmica local daquele equipamento social. Acompanhou-se, também, uma terapeuta ocupacional atuante na atenção básica em saúde, no mesmo território, demarcado pela vulnerabilidade, que engloba Unidades Básicas de Saúde (UBS) e Unidades de Saúde da Família (USF).

Optou-se em fazer o trabalho de observação no mesmo território geográfico, na tentativa de se compreender as diferenças e similaridades de intervençôes destinadas às mesmas características socioeconômicas, priorizando um território de vulnerabilidade social, para atender aos objetivos dessa investigação; realizando, portanto, as observaçóes-participantes na regiâa sul do município de São Carlos.

Elaborou-se relatório diário do acompanhamento de ambos os campos, por meio de roteiro elaborado para este fim, o qual descrevia as atividades realizadas pelas profissionais, seus objetivos, população envolvida e temáticas surgidas a partir daquela intervenção.

Paralelamente à observação participante, lançamos mão do uso de entrevistas a partir de um roteiro semiestruturado que visava conhecer qual era a visão da profissional acerca das especificidades de seu trabalho naquele campo, sua visão sobre a intervenção técnica em contextos de vulnerabilidade social, bem como apreender, num espectro mais amplo, o discurso das terapeutas ocupacionais sobre as açôes que desenvolvem.

No total, obtivemos como sujeitos da pesquisa seis terapeutas ocupacionais que desempenhavam sua ação na área social da cidade de São Carlos e cinco terapeutas ocupacionais que realizavam seu trabalho na rede de atenção básica em saúde do município.

Por fim, os dados foram analisados a partir de análises temáticas advindas do discurso das terapeutas ocupacionais entrevistadas e dos relatórios elaborados nas observações participantes.

Destaca-se que todos os procedimentos de ética em pesquisa foram respeitados, sendo que recebemos autorização das instituiçóes envolvidas para a realização das observaçôes participantes, tanto da Diretoria de Saúde responsável quanto da Coordenação do Equipamento de Atenção ao Jovem; assim como todas as entrevistadas assinaram o Termo de Consentimento Livre e Esclarecido.

\section{Resultados e discussão}

\subsection{O discurso das terapeutas ocupacionais}

Os estudos acerca da área social apontam duas discussôes iniciais presentes na preocupação das terapeutas ocupacionais. A primeira refere-se ao questionamento sobre a compreensão do processo de adoecimento, em suas dimensões individual e coletiva, numa crítica à visão biomédica e à medicalização da sociedade, na perspectiva de inclusão das dimensóes socioculturais e econômicas para a compreensão da dinâmica de vida e da inserção social das pessoas. A segunda questão se fundamenta na proposiçáo que a terapia ocupacional social se desenlaça da mediação saúde-doença, na qual a profissão se alicerça em outros campos de intervenção, incitando o debate de uma especificidade da questáo social (BARROS, 2004; BARROS; LOPES; GALHEIGO, 2007).

Desse modo, para se realizar uma prática na área social condizente com seus preceitos é preciso "transcender a clínica", "[...] superar a necessidade do setting terapêutico e confrontar-se com o território[...]", com a comunidade e os espaços cotidianos (BARROS; GHIRARDI; LOPES, 2002, p. 100). Entretanto, observou-se nas falas de $50 \%$ das terapeutas ocupacionais atuantes na área social uma forte ligação com o campo clínico de intervenção. 
[...] não dá pra dizer que você é um TO só social, porque quando você vê são várias patologias [...] você como profissional da saúde, você vai vê nessa rotina, nesses atendimentos, nessa população (terapeuta ocupacional social 2, p. 1).

Desse modo, nota-se no discurso das terapeutas ocupacionais entrevistadas atuantes na área social ainda a presença de um raciocínio clínico, voltado à saúde, mesmo quando em intervenção social. Tal questão pode apresentar desdobramentos relevantes, uma vez que tais práticas não condizem com os objetivos postulados pelo campo social e a atuação clínica nesse contexto ocasiona o risco de medicalização das ações sociais.

Por outro lado, na fala das demais terapeutas ocupacionais sociais entrevistadas, ou seja, 50\% delas, observou-se uma predominância em torno das temáticas sobre cidadania e direitos sociais, produção de identidades, interpretação da demanda como expressão de necessidades e desejos individuais e coletivos, o trabalho com projetos de vida, indo ao encontro dos conceitos da literatura específica produzida na área social.

Eu acho que é a produção de autonomia, o fortalecimento e a garantia dos direitos desses jovens. Que a gente consiga plantar algumas sementinhas na vida deles pra que eles possam ter [...] pra que eles possam fazer planos de mudança de vida, de projetos de vida (terapeuta ocupacional social 4, p. 2).

Supomos que a não apropriação dos conceitos da área social e de suas metodologias relacionam-se ao fato de haver uma defasagem na formação de profissionais nessa área, identificados em alguns relatos.

[...] porém acho que a nossa formação de graduação a gente aborda muito pouco a TO social. Então, acho que a graduação precisaria investir mais nesse campo (terapeuta ocupacional social 4, p. 3).

[...] eu acho que a formação dentro da graduação, acho que a gente vê muito pouco da área social, pelo menos na minha época de formação (terapeuta ocupacional social 5, p. 4).

A questão da deficiência na formação no nível de graduação permanece no discurso das terapeutas ocupacionais atuantes na atenção básica em saúde. Embora a política do Sistema Único de Saúde (SUS) seja mais antiga que a política do Sistema Único de Assistência Social (SUAS), e possua o reconhecimento da atuação do terapeuta ocupacional em diferentes níveis de atenção, as profissionais ainda demarcam o pequeno conteúdo estudado.

[...] eu acho que até foi uma boa disciplina, mas era uma disciplina de noçóes de saúde coletiva, noçóes de saúde pública, alguma coisa assim [...] do que era SUS, mas assim, não teve visita, não teve algo mais (terapeuta ocupacional - Atenção Básica em Saúde 7, p. 1).

O campo social, por seu turno, tem crescido como espaço de trabalho para os terapeutas ocupacionais, requerendo profissionais habilitados e formados dentro das especificidades da área. Recentemente o Sistema Único de Assistência Social (SUAS), por meio da resolução no17/2011, habilita o terapeuta ocupacional como um dos profissionais para atuar nas especificidades dos serviços socioassistenciais do SUAS, demarcando, assim, a necessidade de formação específica (CONSELHO..., 2011).

Na cidade de São Carlos-SP, especificamente, já se conta com três terapeutas ocupacionais como funcionárias públicas municipais em intervenção no SUAS, no âmbito dos Centros de Referência de Assistência Social (CRAS) e Centros de Referência Especializada de Assistência Social (CREAS). Entretanto, as terapeutas ocupacionais foram realocadas de um concurso específico para a saúde, visto que não se realizou um concurso específico sobre política de assistência social para as pessoas ocuparem esse cargo, podendo se levantar outra hipótese sobre a pouca formação das profissionais para tais atribuiçôes.

[...] não sei, eu acho assim, tá começando [...] e o fato de irem pessoas pra cidadania, né, desse concurso da TO, eu acho que é um marco (terapeuta ocupacional social 2, p. 4).

Espera-se que, num futuro próximo, possamos ter concursos específicos para cada área da terapia ocupacional nos municípios com ampliação de espaços de trabalho para os profissionais, de acordo com as regulamentaçóes de cada campo.

Vê-se, portanto, a primeira semelhança encontrada nos relatos das entrevistadas remete às lacunas da formação acadêmica. A partir de tais dados, levanta-se como hipótese que a área social e a atenção básica em saúde são disciplinas insípidas na graduação em terapia ocupacional, colocadas como coadjuvantes em muitas formaçóes. Desse modo, colocamos como questão pertinente para a discussão a necessidade de um maior investimento das universidades para com o ensino acadêmico dessas áreas, visto que estão se transformando em campos de atuação em expansão para os terapeutas ocupacionais. 
Em relação ao campo da saúde, tal quadro vem sendo modificado, na medida em que a formaçáo para o SUS é preocupação crescente dos cursos de graduação na área da saúde, em geral, com induções específicas do Ministério da Saúde. Entretanto, a formação para a intervenção na área social permanece um desafio a ser incorporado nos diferentes cursos de graduação do país.

Especificamente sobre os recursos utilizados pela terapeuta ocupacional da atenção básica em saúde, notou-se como elemento de presença constante os grupos terapêuticos. Segundo Ballarin (2007), os grupos terapêuticos são espaços que proporcionam aos participantes a possibilidade de experimentar outras formas de se relacionar e de vivenciar situaçóes relativas ao fazer, possibilitando sentido e significado à ação desempenhada. Além disso, há a possibilidade de convivência, relaçáo e troca de vivências e experiências.

A gente tem a linha de cuidado coletivo que são os grupos. Então são vários grupos que eu coordeno, por exemplo, grupo de apoio aos tabagistas, grupo de gestante, grupo de convivência, que é uma tentativa de integrar as pessoas com tratamento na saúde mental e algumas pessoas com deficiência fisica nas rotinas da unidade de saúde (terapeuta ocupacional - Atenção Básica em Saúde 10, p. 1).

Já na terapia ocupacional social o trabalho também se fundamenta na prática coletiva, contudo pelo conceito de oficina de atividades e/ou culturais, diferenciado-se dos propósitos dos grupos terapêuticos. A noção de atividade, por conseguinte, sai da noção de instrumento terapêutico e constitui-se como instrumento de emancipação, de mediação de relaçóes para o foco nas questôes socioeconômicas, e não naquelas terapêuticas (BARROS; GHIRARDI; LOPES, 2002; LOPES, 2006; BARROS; LOPES; GALHEIGO, 2007).

A oficina, como eu disse, ela é bem estruturada [...]. Sempre tem alguns temas que permeiam esse momento. Depois desse momento a gente tem um aquecimento inespecifico, que pode ser qualquer tipo de dinâmica. Depois a dinâmica, propriamente dita, onde a gente trata de temas como a violência, drogas, gravidez na adolescência, sexualidade, entre outros. E aí a gente faz uma dinâmica com as meninas usando diversos recursos, como filme, material artesanal ou alguma coisa mais dinâmica, propriamente dita (terapeuta ocupacional social 4, p. 1).

Observa-se, portanto, que ambos os campos de atuação lançam mão de atividades coletivas como recursos de intervenção. As atividades e a realização de grupos constituem-se como marcas da identidade da profissão, independente da área específica em discussão. Contudo, a aproximação pormenorizada das práticas demonstra objetivos distintos entre as áreas, visto que a área social visa à experimentação e à aprendizagem, com a finalidade de inserção social frente às questóes sociais colocadas; já a saúde estabelece-se mais proximamente do viés terapêutico, com açôes para a reabilitação, promoção da saúde e prevenção.

Quando abordamos especificamente aquele território, demarcado por vulnerabilidades sociais, evidenciaram-se semelhanças logo no início da aproximação, trazidas pelo contexto. As açôes territoriais requerem intervençóes condizentes com a realidade local, a fim de construir propostas que se voltem à compreensão do indivíduo de maneira global, a partir do contexto coletivo no qual se insere, sem restringi-lo às suas necessidades e problemáticas singulares (BARROS; GHIRARDI; LOPES, 2002).

Desse modo, cabe aos terapeutas ocupacionais atuantes tanto na área social quanto na atenção básica em saúde a compreensão do espaço social que utilizam para atenção às pessoas, marcado fortemente pelos contextos de vulnerabilidade social, uma vez que compóem a realidade dos sujeitos, grupos e comunidades acompanhados.

\subsection{A observação da prática: cenas de intervenção nos dois campos em estudo}

Crianças correndo e brincando entre intensa circulação de carros e motos, grupos de pessoas sentadas nas calçadas ou andando pela rua, jovens empinando pipas; é assim que se desenha a maioria das ruas do território estudado, como de regióes periféricas de muitos municípios brasileiros. A referida região, estigmatizada por ser um local periférico e empobrecido da cidade, é composta por um bairro notoriamente conhecido pelos altos índices de desemprego, pobreza, violência e baixos índices de desenvolvimento humano, especialmente no que se refere ao acesso a bens e serviços sociais (CAMPOS et al., 2003; LOPES; SOUZA, 2010).

As profissionais de ambos os campos relatavam tentativas de aproximação com aquela realidade:

Geralmente, eu pauto muito na questão das visitas, de estar indo na casa, de saber como é a rotina, como que é o cotidiano, de adequação do ambiente (terapeuta ocupacional 9 - Atençáo Básica em Saúde, p. 8). 
As propostas eram que elas mostrassem pra gente um pouco do bairro, um pouco do que elas gostam de fazer, de onde elas moram. E a gente saiu para o território antes da criação [do grupo] para poder conhecer e saber onde que estavam (terapeuta ocupacional social 4, p. 2).

$\mathrm{Na}$ convivência com a regiāo estudada, demarcada pela vulnerabilidade social, ficaram evidenciadas questôes relacionadas à precarização do trabalho formal. Associado a este fator, o mundo da ilegalidade apresentou-se como elemento constitutivo daquele espaço, com forte relação com o universo das drogas e, mais especificamente, do tráfico de drogas. Tais fatores estavam presentes e eram discussóes constantes em ambas as equipes: na unidade de saúde assim como no centro de lazer voltado aos jovens.

Desse modo, têm-se o cenário da intervenção como ponto de partida, que aproxima as duas práticas estudadas, na medida em que a realidade dos sujeitos, grupos e coletivos é elemento intrínseco e inerente ao trabalho do terapeuta ocupacional em qualquer campo de atuação.

As características daquele contexto requeriam o estabelecimento de relaçóes de confiança para que a ação técnica pudesse ser desenvolvida. Assim, o trabalho em terapia ocupacional demonstrava necessidade de desenvolvimento de vínculos para que pudesse atingir, verdadeiramente, aquela comunidade. Esteve presente a criação de estratégias para fortalecimento do vínculo com as pessoas em ambas as intervenções acompanhadas.

$\mathrm{Na}$ terapia ocupacional social a importância do vínculo se deve ao fato de que, na ausência dele, não se consegue acessar as reais demandas, necessidades e desejos das pessoas, resultando no insucesso das intervençôes (LOPES, 2006). No acompanhamento das atividades, notou-se que o processo de vinculação acontecia de forma lenta e gradual, assim como nas experiências vivenciadas por Lopes, Borba e Cappellaro (2011) e Lopes, Malfitano e Borba (2006). Partia-se da aproximação do sujeito através das oficinas de atividades que, por meio desta, elegia uma pessoa da equipe, mantendo-a como referência às suas demandas e relatos pessoais.

Já no âmbito da saúde o vínculo com pacientes é também um importante instrumento, uma vez que possibilita maior adesão ao tratamento, ampliando a eficácia das açôes de saúde e favorecendo a participação do usuário durante o processo terapêutico. $\mathrm{Na}$ prática observada na atenção básica em saúde, a terapeuta ocupacional dispunha do vínculo como passo inicial de um tratamento, adquirindo-o por meio da escuta qualificada e do acolhimento em saúde. Notou-se que era estabelecido de forma mais rápida e pontual, uma vez que os usuários dos serviços públicos de saúde, principalmente daquela região, depositavam nos profissionais de saúde grande pujança, colocando-os como referência em seu processo saúde-doença. Partia-se da demanda e procura espontânea dos usuários, modificando as características do processo.

Outro elemento observado constituiu-se na composição de equipes de trabalho pelos terapeutas ocupacionais. $\mathrm{Na}$ atenção básica em saúde, a terapeuta ocupacional estava inserida em equipes multiprofissionais por meio do apoio matricial. De acordo com Campos e Dommiti (2007), o apoio matricial é uma metodologia de trabalho complementar com objetivo de assegurar e dar suporte técnico às equipes e profissionais encarregados da atenção à saúde, como em Unidades de Saúde da Família (USF).

Assim, esse suporte acontecia por meio de reuniōes, nas quais os profissionais das unidades traziam casos e discutiam possibilidades e formas de tratamento, com sugestões e esclarecimentos dos profissionais responsáveis pelo matriciamento, como a terapeuta ocupacional acompanhada.

Nas atividades acompanhadas no campo social, a equipe de atuação, responsável pelas ações práticas, era composta apenas por terapeutas ocupacionais, profissionais e estudantes. A equipe também desempenhava papéis de articulador e de suporte técnico aos profissionais atuantes no centro da juventude, assessorando-os na elaboração técnica de proposiçóes e nos relacionamentos com os jovens, entre outras açóes.

Portanto, observa-se que o trabalho em equipe e sua articulação aparecem como outros elementos de trabalho do terapeuta ocupacional, utilizados nos dois campos estudados, como ponto de similaridade, realizando o papel de articulador de saberes.

A prática terapêutico-ocupacional também possui enfoque distinto na dicotomia saúde-social quando observada a intervenção diretamente no domicílio do indivíduo acompanhado. A visita domiciliar, como técnica para levantamento de informaçōes, é utilizada por diversas profissóes, constituindo-se como um momento para a escuta qualificada, o vínculo e o acolhimento de indivíduos ou famílias que demandam cuidados.

Na saúde foi acompanhada uma visita domiciliar a uma senhora idosa, e com obesidade mórbida, a qual não saía de casa e não realizava nenhuma atividade física, assim a terapeuta ocupacional traçou como demanda o trabalho voltado à promoção de 
sua saúde, prevenção de outros agravos, melhora na qualidade de vida por meio da interferência em suas atividades cotidianas, usando a criação de vínculo como meio para tal.

A área social, por sua vez, também utiliza da visita domiciliar como um instrumento de informação e de criação/estreitamento do vínculo, assim como para encaminhamentos demandados da aproximação com os jovens, naquela experiência. Foi acompanhada uma visita a um adolescente e aos seus familiares com intuito de propor seu encaminhamento às atividades esportivas e escolares. Naquele momento, o objetivo era a viabilização da ida da adolescente à escola, por se tratar de etapa fundamental da vida adolescente, apropriando-a desse direito como cidadá. Observa-se, portanto, que o objetivo central se difere, ao passo que sua realização propóe investigar a história do sujeito com vistas a buscar novos projetos de inserção e perspectivas de efetivação de açôes sociais.

Os desdobramentos do processo de vinculação refletiram em ações individualizadas e mais aprofundadas entre a profissional e o sujeito. Na saúde, principalmente nos atendimentos ambulatoriais e/ou domiciliares, acompanharam-se açôes de adaptaçôes e treinos para atividades de vida diária; estímulos para o autocuidado, autoestima e autoconhecimento; reestruturação do cotidiano; entre outros.

Eu foco muito no atendimento individual, eu tenho uma postura meio tradicional assim, eu gosto desse contato no individual. Sei que tem muita crítica na atenção básica, o pessoal gosta muito de trabalhar em grupo, de fazer outro tipo de estratégia de atendimento, mas têm alguns casos que eu gosto de atender no individual, principalmente quando é questão de deficiência fisica ou alguma coisa que eu precise fazer um treino de $A V D$ ou reestruturação de cotidiano (terapeuta ocupacional - Atenção Básica em Saúde 9, p. 3).

Já no campo social, os denominados acompanhamentos individuais refletem um acolhimento das demandas do outro, em responsabilidade conjunta para a resolução de problemas, como articulaçóes com familiares, com escolas, com o mercado de trabalho, tendo a inserção social como eixo de ação.

Acho que o terapeuta ocupacional [social] tem um olhar para os acompanhamentos individuais e que têm produzido muito material pra gente pensar nessa ampliação do campo da terapia ocupacional (terapeuta ocupacional social 4, p. 1/2).

Compreende-se, portanto, que as intervençóes individualizadas são pontos que distinguem a prática da terapia ocupacional social e na atençáo básica em saúde, visto que a diferença já se dá na própria nomenclatura das ações: atendimento e acompanhamento.

O atendimento em saúde pelo viés do SUS é calcado em objetivos como promover a integralidade da assistência, a equidade, a promoçáo e prevenção de agravos e a revisão das práticas cotidianas (CASATE; CORRÊA, 2005). Estabelecem-se metas para um Plano Terapêutico Singular, a partir das necessidades do outro. Já o acompanhamento individual empregado na área social é uma ferramenta utilizada para promover o fortalecimento das redes sociais de suporte, com vistas a proporcionar maior inserção social do indivíduo, não abordando questóes "terapêuticas" ou da relação saúde e doença. Por meio de estratégias diversas, volta-se para uma leitura conjunta das necessidades apresentadas, tendo como viés sua responsabilidade profissional política, técnica e ética na função de articular redes sociais, redes comunitário-familiares e de serviços e órgãos públicos (LOPES; BORBA; CAPPELLARO, 2011).

Assim demarca-se a diferença de recursos utilizados para açóes individualizaas em ambos os campos.

Quando nos voltamos especificamente ao trabalho técnico em contextos de vulnerabilidade social, observam-se proposições diferentes quando realizadas pelo viés da área da saúde ou da área social. No âmbito da saúde, a vulnerabilidade social é encarada como

[...] um conjunto de aspectos que váo além do individual, abrangendo aspectos coletivos, contextuais, que levam à suscetibilidade a doenças ou agravos. (SÁNCHEZ; BERTOLOZZI, 2007, p. 323).

Além de também levar em conta aspectos que se relacionam à disponibilidade ou à ausência de recursos destinados à proteção dos indivíduos. Dessa maneira, a utilização do conceito na atenção básica em saúde tende a apoiar novas práticas que se dissociem de explicaçóes relacionadas ao paradigma unicausal das doenças, nas quais o cuidado às pessoas surja de açôes em conjunto com outros setores da sociedade, por meio da intersetorialidade (SÁNCHEZ; BERTOLOZZI, 2007). Entende-se, portanto, que a vulnerabilidade social é uma condição pela qual a ação da saúde pode perpassar, devendo construir intervençōes para se trabalhar com ela.

Em contraponto, na área social a vulnerabilidade se constrói como instrumento de trabalho, na qual a questão socioeconômica se faz como elemento central da intervenção, na medida em que o recorte escolhido se dá pela intervenção em contextos desfavorecidos economicamente. Portanto, a atuação intersetorial 
Tabela 1. Comparação dos objetivos empregados para os recursos utilizados nos diferentes campos.

\begin{tabular}{|c|c|c|}
\hline Recurso de intervenção & Campo & Objetivo \\
\hline \multirow[t]{2}{*}{ Atividade grupal } & Área Social & $\begin{array}{l}\text { Propor atividades voltadas à experimentação e à } \\
\text { aprendizagem, principalmente aquelas ligadas às questões } \\
\text { sociais. Utilizada como elemento-meio de ação para } \\
\text { aproximação, vinculação e criação de espaços de convivência. }\end{array}$ \\
\hline & $\begin{array}{l}\text { Atenção Básica } \\
\text { em Saúde }\end{array}$ & $\begin{array}{l}\text { Propor atividades a fim de promover o bem-estar físico } \\
\text { e mental de seus participantes, com vistas à promoção, } \\
\text { prevenção e reabilitação. }\end{array}$ \\
\hline \multirow[t]{2}{*}{ Visita domiciliar } & Área Social & $\begin{array}{l}\text { Investigar a história do sujeito, buscar aproximação, discutir } \\
\text { elementos significativos de sua vida com vistas a buscar } \\
\text { novos projetos de inserção e perspectivas de efetivação de } \\
\text { ações sociais. }\end{array}$ \\
\hline & $\begin{array}{l}\text { Atenção Básica } \\
\text { em Saúde }\end{array}$ & $\begin{array}{l}\text { Investigar a história do sujeito, buscar aproximação, discutir } \\
\text { elementos para a promoção de saúde, prevenção de doenças, } \\
\text { ações no cotidiano para melhora na qualidade de vida. }\end{array}$ \\
\hline \multirow{2}{*}{$\begin{array}{c}\text { Acompanhamento/ } \\
\text { Atendimento individual }\end{array}$} & Área Social & $\begin{array}{l}\text { Criação de estratégias para se alcançar a inserção social do } \\
\text { sujeito acompanhado por meio de acolhimento das demandas } \\
\text { do outro, em responsabilidade conjunta para a resolução de } \\
\text { problemas, como articulações com familiares, com a rede de } \\
\text { equipamentos sociais locais etc. }\end{array}$ \\
\hline & $\begin{array}{l}\text { Atenção Básica } \\
\text { em Saúde }\end{array}$ & $\begin{array}{l}\text { Atendimento terapêutico, com foco na promoção de saúde } \\
\text { e qualidade de vida, como ações de adaptações e treinos } \\
\text { para atividades de vida diária; estímulos para o autocuidado, } \\
\text { autoestima e autoconhecimento; reestruturação do cotidiano. }\end{array}$ \\
\hline
\end{tabular}

também se faz necessária para a possibilidade de articulação de recursos em determinada regiáo, notadamente marcada por estigmas sociais. Segundo Malfitano (2005), a área social se constitui como um campo, de caráter mais geral e interdisciplinar, composto por diversos núcleos e suas especialidades, os quais são formados por uma dada área com um dado profissional. A autora afirma que o trabalho em rede determina maior efetividade para a população assistida, na medida em que visualiza, de forma integral, suas demanadas.

Têm-se, para as duas áreas trabalhadas, a vulnerabilidade social e a intersetorialidade como pontos de partida e de similaridade, contudo com objetivos de trabalho distintos, sendo para a saúde o intuito voltado para a prevenção de doenças e a promoção da saúde, e, para a área social, o objetivo de discussão de direitos e o vislumbre de possibilidades de efetivação de projetos voltados para a inserçáo social, nos níveis individual e/ou coletivo.

Portanto, a atuação da terapia ocupacional em contextos de vulnerabilidade nos campos social e atenção básica em saúde possuem diferenças intrínsecas aos cuidados que cada uma delas estabelece aos sujeitos atendidos e acompanhados, sendo distinto o enfoque da saúde e o enfoque social dessa modalidade de assistência.

Apresentamos, na Tabela 1, uma síntese das principais ações realizadas pelas terapeutas ocupacionais em ambos os campos e as distinçóes entre elas, segundo seu discurso e observaçóes feitas.

\section{Considerações finais}

A partir de elementos de necessidade de distinção e especificidades nos campos, pudemos observar a concretude de dois universos distintos de atuação: a terapia ocupacional na área social e a terapia ocupacional na atenção básica em saúde. Muitas vezes lidas pela similaridade dos "contextos sociais", vale destacar que a intervençáo em espaços de vulnerabilidade socioeconômica não define, por si, a natureza do trabalho desempenhado, na medida em que se faz necessário o olhar aproximado aos objetivos, recursos e especificidades de cada intervenção, para que se possa delimitar as intençôes com a intervenção, os conhecimentos com os quais dialoga, sua finalidade e habilidades e competências requeridas para o seu desenvolvimento.

Destacamos a necessidade de preocupação com as lacunas na formação graduada para que se possa voltar a atenção para a capacitação técnica, política e ética de profissionais para ambos os campos. Pelos relatos apresentados, pautamos a necessidade de discussão acerca da necessidade de um maior investimento das universidades para com o ensino acadêmico de ambas as áreas. 
Contextos de vulnerabilidade social têm marcado práticas profissionais e requerem atenção e compreensão aprofundadas. Demandas como a articulação entre equipamentos sociais formais e informais disponíveis na região, a compreensão de demandas individuais e/ou coletivas dos sujeitos, assim como atuar sob contextos onde impera a ilegalidade, com predominância para a organização do tráfico de drogas e suas consequências, como crimes e mortes, são pontos que aproximam a prática tanto de terapeutas ocupacionais da saúde quanto da área social e interpelam as possibilidades e limites do desenvolvimento de trabalhos. Tais apontamentos estendem-se a todos os técnicos que se encontram trabalhando em regióes periféricas, independente de sua formação de base. Com isso, têm-se o cenário da intervenção como ponto de partida, que aproxima as duas práticas estudadas, na medida em que a realidade dos sujeitos, grupos e coletivos é elemento intrínseco e inerente ao trabalho do terapeuta ocupacional em qualquer campo de atuação.

O espaço marcado por vulnerabilidades compóe também distinçóes importantes em relação às duas áreas de atuaçáo, quando se volta a seus objetivos específicos. A saúde foca-se na prevenção de doenças suscetíveis pela situação local e a área social utiliza-se da vulnerabilidade como instrumento de trabalho e de reflexão para se pensar as possibilidades de inserção social daqueles sujeitos e comunidades.

Além das similaridades e distinçôes aqui apresentadas, observou-se durante a pesquisa a estreita relação que o trabalho em equipes multiprofissionais proporciona à terapia ocupacional e aos outros profissionais. Compreendendo a ação por meio de núcleos de especificidades que compóem um campo de atuação comum, o trabalho intersetorial se faz quando tais núcleos se casam e realizam intervençôes similares e conjuntas. Portanto, tem-se que a intersetorialidade se faz presente nos dois campos estudados evidenciando que o trabalho em rede determina a maior efetividade de intervenção à população assistida.

Por fim, através da comparaçáo do trabalho da terapia ocupacional na atenção básica em saúde e na área social, concluímos que se trata de campos específicos, com questôes inerentes que requerem atuaçóes singulares e distintas, e, portanto, formaçóes e habilidades específicas.

Consideramos necessário aos terapeutas ocupacionais a compreensão das práticas desempenhadas a fim de que realizem intervençôes condizentes com as necessidades do campo, inferindo em maiores contribuiçóes ao público para o qual desempenha sua ação. É de fundamental importância que os terapeutas ocupacionais conheçam as particularidades e funçôes de cada campo, visando atuaçōes responsáveis e efetivas, com respostas coerentes às demandas da população assistida.

\section{Referências}

BALLARIN, M. L. G. Abordagens grupais. In: CAVALCANTI, A.; GALVÃO, C. Terapia ocupacional: Fundamentação \& prática. Rio de Janeiro: Guanabara Koogan, 2007. p. 38-42.

BARROS, D. D.; GHIRARDI, M. I. G.; LOPES, R. E. Terapia ocupacional social. Revista de Terapia Ocupacional da USP, São Paulo, v. 13, n. 3, p. 95-103, 2002.

BARROS, D. D. Terapia ocupacional social: o caminho se faz ao caminhar. Revista de Terapia Ocupacional da USP, São Paulo, v. 15, n. 3, p. 90-7, 2004. http://dx.doi. org/10.11606/issn.2238-6149.v15i3p90-97

BARROS, D. D.; LOPES, R. E.; GALHEIGO, S. M. Terapia Ocupacional Social: Concepçóes e Perspectivas. In: CAVALCANTI, A.; GALVĀO, C. (Org.). Terapia Ocupacional: Fundamentação e Prática. Rio de Janeiro: Guanabara Koogan, 2007. p. 347-353.

BRASIL. Ministério da Saúde. Secretaria Nacional de Assistência à Saúde. $A B C$ do SUS: doutrinas e princípios. Brasília: Imprensa Oficial, 1990.

BRASIL. Ministério da Saúde. Portaria no 154 de 24 de janeiro de 2008. Cria os Núcleos de Apoio à Saúde da Família - NASF. Diário Oficial da República Federativa do Brasil, Brasília, DF, 25 jan. 2008. Seção 1.

BRASIL. Ministério da Saúde. Brasil. Atenção Básica e a Saúde da Família. Brasília: Imprensa Oficial, 2010. Disponível em: $<$ http://dab.saude.gov.br/atencaobasica. php>. Acesso em: 23 mar. 2010.

CAMPOS, G. W. S.; DOMITTI, A. C. Apoio matricial e equipe de referência: uma metodologia para gestấo do trabalho interdisciplinar em saúde. Cadernos de Saúde Pública, Rio de Janeiro, v. 23, n. 2, p. 399-407, 2007. http://dx.doi.org/10.1590/S0102-311X2007000200016 CAMPOS, S. E. A. et al. O lazer cotidiano do Jardim Gonzaga - São Carlos. In: ENCONTRO NACIONAL DE RECREAÇÃO E LAZER - LAZER E TRABALHO, 2003, 15., Santo André. Anais... Santo André: UFSCar, 2003. Disponível em: <http://www. ufscar.br/ defmh/spqmh/pdf/enarelgonz.PDF $>$. Acesso em: 02 dez. 2009.

CASATE, J. C.; CORRÊA, A. K. Humanização do atendimento em saúde: conhecimento veiculado na literatura brasileira de enfermagem. Revista LatinoAmericana de Enfermagem, Ribeirão Preto, v. 13, n. 1, p. 105-111, 2005. http://dx.doi.org/10.1590/ S0104-11692005000100017

CASTEL, R. Da indigência à exclusão, a desfiliação. Precariedade do trabalho e vulnerabilidade relacional. In: LANCETTI, A. (Org.). Saúde loucura, n. 4. São Paulo: Hucitec, 1994. p. 21-48. 
CONSELHO FEDERAL DE FISIOTERAPIA E TERAPIA OCUPACIONAL - COFFITO. Resolução n. 383/2010, de 22 de dezembro de 2010. Define as competências do Terapeuta Ocupacional nos Contextos Sociais e dá outras providencias. Diário Oficial da República Federativa do Brasil, Brasília, DF, 25 nov. 2010. Seção 1, n. 225.

CONSELHO NACIONAL DE ASSISTÊNCIA SOCIAL - CNAS. Resolução no 17/2011, de 20 de julho de 2011. Ratificar a equipe de referência definida pela Norma Operacional Básica de Recursos Humanos do Sistema Único de Assistência Social - NOB-RH/SUAS e Reconhecer as categorias profissionais de nível superior para atender as especificidades dos serviços socioassistenciais e das funçôes essenciais de gestão do Sistema Único de Assistência Social - SUAS. Diário Oficial da República Federativa do Brasil, Brasília, DF, 21 jul. 2011. Seção 1.

COTTA, R. M. M. et al. Pobreza, injustiça, e desigualdade social: repensando a formação de profissionais de saúde. Revista Brasileira de Educação Médica, Rio de Janeiro, v. 32, n. 3, p. 278-286, 2007. http://dx.doi.org/10.1590/ S0100-55022007000300010

FARIA, R. M.; BORTOLOZZI, A. Espaço, território e saúde: Contribuiçóes de Milton Santos para o tema da geografia da saúde no Brasil. $R A^{\prime} E$ GA, Curitiba, n. 17, p. 31-41, 2009.

HAESBAERT, R. Da Desterritorialização à Multiterritorialidade. In: ENCONTRO DE GEÓGRAFOS DA AMÉRICA LATINA, 10. 2005, São Paulo. Anais...São Paulo: USP, 2005. p. 6774-6792. JARDIM, T. A.; AFONSO, V. C.; PIRES, I. C. A terapia ocupacional na Estratégia de Saúde da Família - evidências de um estudo de caso no município de São Paulo. Revista de Terapia Ocupacional da USP, São Paulo, v. 19 n. 3, p. 167-175, 2008. http://dx.doi.org/10.11606/issn.22386149.v19i3p167-175

LOPES, R. E. Terapia Ocupacional social e a infância e a juventude pobres: experiências do núcleo UFSCar do Projeto Metuia. Cadernos de Terapia Ocupacional da UFSCar, São Carlos, v. 14, n. 1, p. 5-14, 2006.

LOPES, R. E.; MALFITANO, A. P. S.; BORBA, P. L. $\mathrm{O}$. O processo de criação de vínculo entre adolescentes em situaçáo de rua e operadores sociais: compartilhar confiança e saberes. Quaestio: Revista de Estudos de Educaçấo, Sorocaba, v. 8, n. 1, p. 121-131, 2006.

LOPES, R. E. Redes Sociais de Suporte. In: PARK, M. B.; FERNANDES, R. S.; CARNICEL, A. Palavras-chave em educação não formal. Holambra: Editora Setembro, 2007. p. 249-250.

LOPES, R. E. et al. Juventude pobre, violência e cidadania. Saúde e Sociedade, São Paulo, v. 17, n. 3, p. 63-76, 2008. http://dx.doi.org/10.1590/S0104-12902008000300008

LOPES, R. E. et al. Educação profissional, pesquisa e aprendizagem no território: notas sobre a experiência de formação de terapeutas ocupacionais. O Mundo da Saúde, São Paulo, v. 34, n. 2, p. 140-7, 2010.

LOPES, R. E; SOUZA, L. B. Memória e Ação Territorial: da história do Jardim Gonzaga às bases de intervenção em Terapia Ocupacional Social. São Carlos: UFSCar/ Pró-Reitoria de Pesquisa, 2010. Relatório de Pesquisa.

LOPES, R. E.; BORBA, P. L. O.; CAPPELLARO, M. Acompanhamento individual e articulação de recursos em Terapia Ocupacional Social: compartilhando uma experiência. O Mundo da Saúde, São Paulo, v. 35, n. 2, p. 233-238, 2011.

MALFITANO, A. P. S. Campos e núcleos de intervençāo na terapia ocupacional social. Revista de Terapia Ocupacional da USP, São Paulo, v. 16, n. 1, p. 1-8, 2005. http://dx.doi.org/10.11606/issn.2238-6149.v16ilp1-8

MEIHY, J. C. S. B. Manual de História Oral. 2. ed. São Paulo: Ediçôes Loyola, 1998.

MINAYO, M. C. S. et al. Pesquisa Social: Teoria, Método e Criatividade. Petrópolis: Editora Vozes, 2002.

OLIVER, F. C. et al. Reabilitação no território: construindo a participação na vida social. Revista de Terapia Ocupacional da USP, Sáo Paulo, v. 12, n. 1-3, p. 15-22, 2001.

SÁNCHEZ, A. I. M.; BERTOLOZZI, M. R.Pode o conceito de vulnerabilidade apoiar a construção do conhecimento em Saúde Coletiva. Ciência \& Saúde Coletiva, Rio de Janeiro, v. 12, n. 2, p. 319-324, 2007. http://dx.doi.org/10.1590/S1413-81232007000200007 UNIVERSIDADE DE SÃO PAULO - USP. Definição de Terapia Ocupacional. USP, 1997. Mimeo.

\section{Contribuição dos Autores}

Ana Paula Serrata Malfitano: Contribuiu na concepção do trabalho, na análise dos dados e na elaboração e redação do texto. Pamela Cristina Bianchi: Contribuiu na concepção do trabalho, na coleta e organização dos dados, na análise, elaboração e redação do texto.

\section{Notas}

${ }^{1}$ Grupo interinstitucional de estudos, formação e açôes pela cidadania de crianças, adolescentes e adultos em processos de ruptura das redes sociais de suporte. Criado em 1998 por docentes de terapia ocupacional de três universidades paulistas: Pontifícia Universidade Católica de Campinas (PUC-Campinas), Universidade Federal de São Carlos (UFSCar) e Universidade de São Paulo (USP). Desde entáo, sua proposta tem sido desenvolver projetos no âmbito do ensino, da pesquisa e da extensão em terapia ocupacional social. Atualmente mantém os núcleos da Universidade de São Paulo (USP), da UFSCar (BARROS; LOPES; GALHEIGO, 2007) e da Universidade Federal de São Paulo (UNIFESP). 